\title{
The Influence of Lead Sulfate on Chloride Transport Properties in Cementitious Materials
}

\author{
X.F. Wang ${ }^{1, a}$, Y.B. Yuan ${ }^{1, b}$, Z.P. Chen ${ }^{1, c}$, N.X. $\operatorname{Han}^{1, d}$ and F. Xing ${ }^{1, e}$ \\ ${ }^{1}$ Guangdong Key Laboratory of Durability in Coastal Civil Engineering, College of Civil Engineering, \\ Shenzhen University, Shenzhen, Guangdong 518060, China

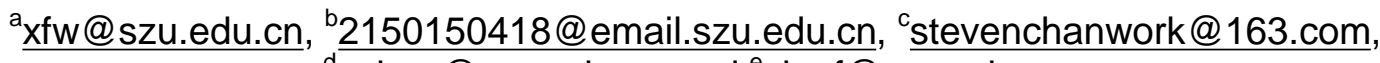 \\ dnxhan@szu.edu.cn and exingf@szu.edu.cn
}

Keywords: ions transport; sulfate damage; chloride; chemical trigger

Abstract. In this study, the influence of lead sulfate on the transport of chloride in mortar was investigated by chloride ion permeation test. The changes of cement hydration products in cement-based materials containing lead sulfate were observed by scanning electron microscopy (SEM).The results show that the free chloride ions in the concrete decrease when the lead sulfate is added. Lead sulfate can also lead the formation of the ettringite,which can acclerate chloride transport.

\section{Introduction}

The corrosion degeneration of reinforcing steel bars in concrete structures has become a world-wide problem to many civil infrastructures. It has been proved that chloride is the main cause of steel bars corrosion [1].In order to reduce this phenomenon caused by chloride intrusion, the traditional methods are to use low permeability concrete and add corrosion inhibitors [2,3]. However, these two methods have many disadvantages in practical applications. Recent years, the microcapsule self-healing concrete based on the principle of bionics has occupied a place in the field of functional materials with its intelligent perception and immediate healing [4-6]. Xiong et al. [7] proposed the microcapsule self-healing system based on the chloride ion-triggered response mechanism. This system can effectively prevent the intrusion of chloride ions.

Sulfate damage has always been one of the focuses of concrete durability researches. They are invaded into concrete by a great deal of methods and can react with hydrated products of cement, which causes the concrete expanding, cracking, peeling, and eventually losing strength and integrity [8]. On the one hand, the sulfate has a negative impact on the concrete structure; on the other hand, some sulfates, such as lead sulfate, can react with chloride ions. Using this feature, lead sulfate can be embedded in organics such as hexadecane/poly-methyl methacrylate (PMMA), which can be prepared into the microcapsule wall [9]. At this point, the role of sulfate is beneficial.

In this study, the effect of lead sulfate on the macroscopic permeability of chloride ions is investigated referenced to the Nordic standard NTBUILD443 [10]. The effect of lead sulfate on micro-pore structure of mortar is studied by the analysis techniques of SEM.

\section{Materials and preparation of mortar specimens}

To build the cementitious composites mixed with lead sulfate, the following materials were used: (1) China Portland Cement GB-175-2007 P II 42.5R type from Guangzhou Zhujiang Cement L .td Company (Guangzhou, China); (2) drinkable tap water; (3) GB/T17671-1999 ISO standard sand from Xiamen Isiou L .td Company. Company (Xiamen, China); (4) plumbous sulphate from Shanghai Zhanyun Chemical L .td Company (Shanghai, China).

The ratios of water to cement and cement to sand of the specimens were 0.5 and $1: 3$, respectively. The mortar dimension is $\Phi 100 \mathrm{~mm} \times 50 \mathrm{~mm}$. The penetration time, grinding depth is shown in Table 1. 
Table 1

The group number of the specimens and its processing method

\begin{tabular}{ccccccc}
$\begin{array}{c}\text { Group } \\
\text { Number }\end{array}$ & $\begin{array}{c}\text { Sample } \\
\text { Number }\end{array}$ & $\begin{array}{c}\text { The Content of } \\
\text { the Lead Sulfate }\end{array}$ & $\begin{array}{c}\text { Penetration } \\
\text { Time (Days) }\end{array}$ & $\begin{array}{c}\text { Grinding } \\
\text { Depth (mm) }\end{array}$ & $\begin{array}{c}\text { Layers } \\
\text { of } \\
\text { Grinding }\end{array}$ & $\begin{array}{c}\text { The Depth of } \\
\text { each layer } \\
(\mathbf{m m})\end{array}$ \\
\hline 1 & A1-1 & $0 \%$ & 70 & 15 & 15 & 1 \\
\hline 2 & A1-2 & $4 \%$ & 70 & 15 & 15 & 1 \\
\hline 3 & A1-3 & $6 \%$ & 70 & 15 & 15 & 1 \\
\hline 4 & A2-1 & $0 \%$ & 90 & 20 & 20 & 1 \\
\hline 5 & A2-2 & $4 \%$ & 90 & 20 & 20 & 1 \\
\hline 6 & A2-3 & $6 \%$ & 90 & 20 & 20 & 1 \\
\hline 7 & A3-1 & $0 \%$ & 140 & $0-20$ & 20 & 1 \\
\hline 8 & A3-2 & $4 \%$ & 140 & $20-40$ & 10 & 2 \\
\hline 9 & \multirow{2}{*}{ A3-3 } & $6 \%$ & 140 & $20-40$ & 10 & 2 \\
\hline
\end{tabular}

\section{Bulk Diffusion Test}

The prepared specimens are placed in a thermostatic chamber for the bulk diffusion test referred to the Nord-test NTBUILD443 [10]. All surfaces of the test specimen except the one to be exposed are then dried at room temperature to a stable white-dry condition and given an approx.1 mm thick epoxy coating. The percentage of chloride ions at different grinding depths were measured and drawn in Fig. 1 (AASHTO Designation: T 260-97 (2009) [11].

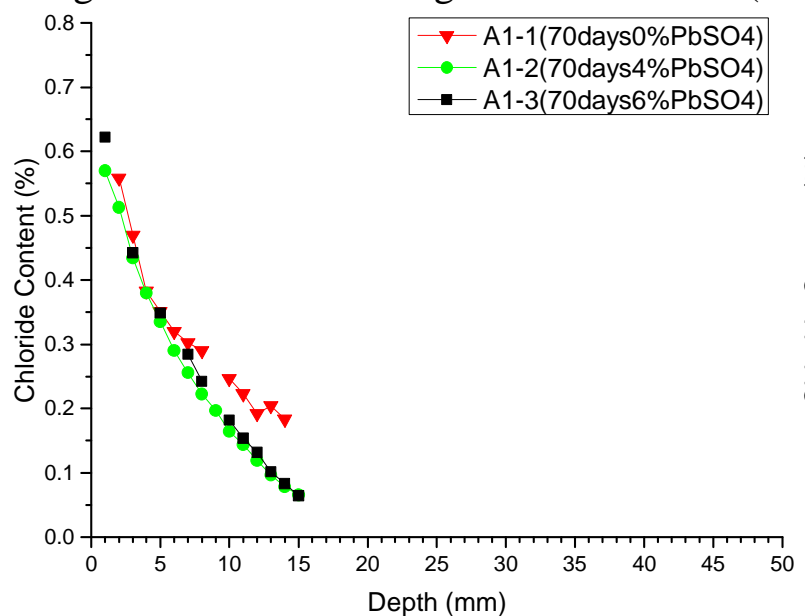

(a)70days

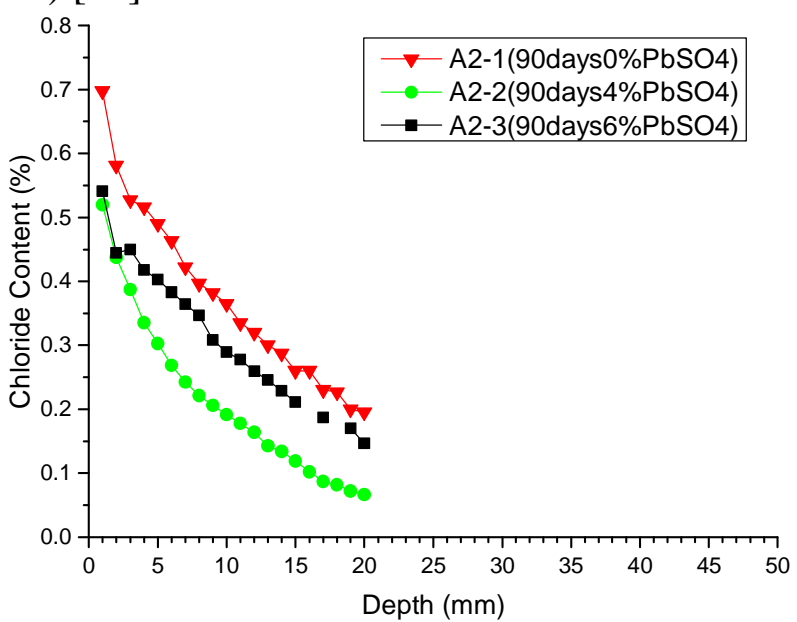

(b)90days 


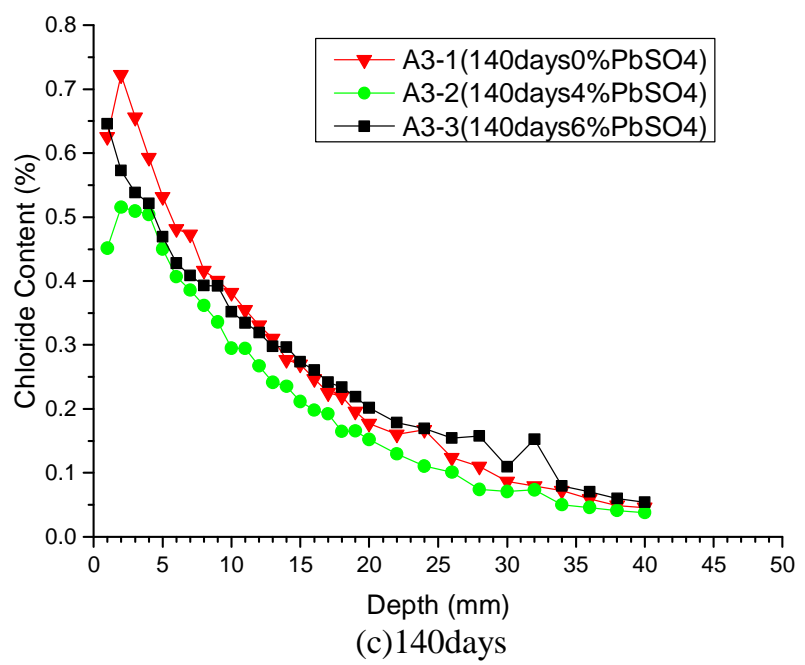

Fig. 1 Chloride profile

\section{SEM analysis}

The SEM analysis is conducted by using Quanta TM 250FEG environmental scanning electron microscopy (SEM). The surface area of cement-based materials is observed with $1 \mathrm{~K}-20 \mathrm{~K}$ magnification. The images observed are shown in Fig. 2.

As can be seen from Fig. 2, the hexagonal material is present in all test blocks. Mehta mentioned [12] that sulfate reacts with cement hydration products to produce ettringite and gypsum, and ettringite microstructure is hexagonal, thus we infer that the hexahedron is ettringite. And its quantity increases with the increase of the amount of lead sulphate and the ponding days.

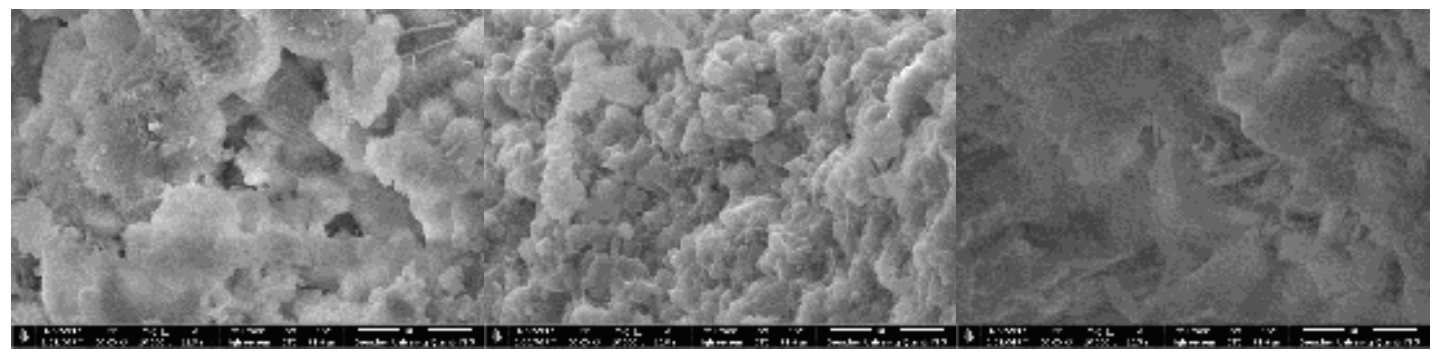

(a) 90Days, $0 \% \mathrm{P}_{\mathrm{b}} \mathrm{SO}_{4}$

(b) 90 Days, $4 \% \mathrm{P}_{\mathrm{b}} \mathrm{SO}_{4}$

(c) 90 Days, $6 \% \mathrm{P}_{\mathrm{b}} \mathrm{SO}_{4}$

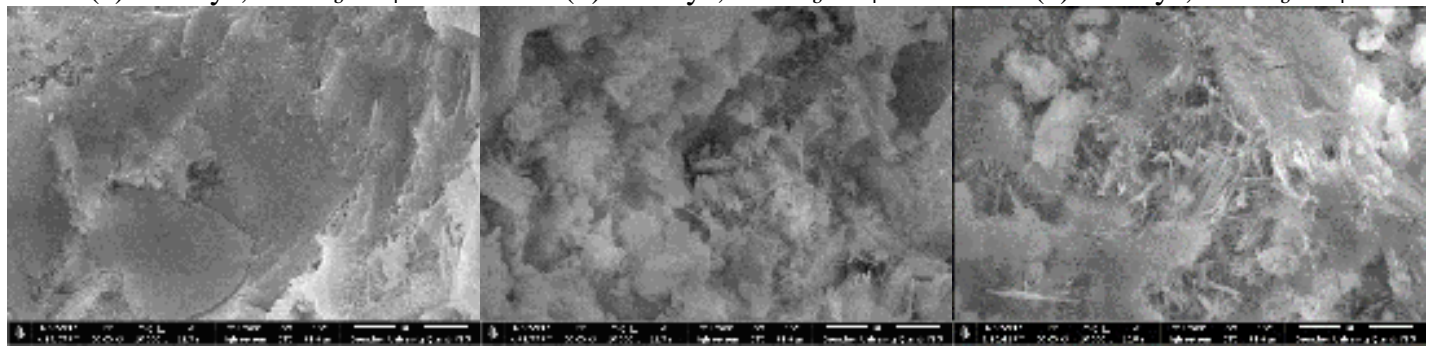

(d) 140Days, $0 \% \mathrm{P}_{\mathrm{b}} \mathrm{SO}_{4}$

(e) 140Days, $4 \% \mathrm{P}_{\mathrm{b}} \mathrm{SO}_{4}$

(f) 140Days, $6 \% \mathrm{P}_{\mathrm{b}} \mathrm{SO}_{4}$

Fig. 2 SEM Microstructure

\section{Effect of lead sulfate on chloride transport characteristic}

When lead sulfate is added into the mortar specimens, chloride in the pore solution can react with lead sulfate, whose reaction equation is shown as Eq. 1. The occurrence of chemical reactions reduces the free chloride ion content. We define this action as a positive effect. However, at the same time, sulfate was introduced. Which can interact with cement hydration products to produce ettringite and gypsum. Their volume is greater than the reactants. This increase clogs the pores in the test blocks, seriously, it will causes a slight expansion of mortar specimens. This accelerates the diffusion 
of chloride ions. We define this effect as a negative effect. When the penetration time is 70days and 90days, positive effect is greater than negative one. The intensity of the negative effect enhances with the increase of the content of lead sulfate and infiltration time. The result of the negative effect is that, when the penetration time is 90days, the free chloride ion percentage of the mortar specimens with Lead sulfate content of $6 \%$ is greater than that of $4 \%$. When the permeation time is 140days, the free chloride ion percentage of mortar specimens with lead sulfate content of $6 \%$ is larger than that of $0 \%$.

$$
\mathrm{P}_{b} \mathrm{SO}_{4}+4 \mathrm{Cl}^{-}=\mathrm{PbCl}_{4}^{2-}+\mathrm{SO}_{4}^{2-}
$$

\section{Conclusions}

From the present study the following conclusions can be drawn:

I The addition of lead sulphate can lead the formation of the ettringite. Its quantity increases with the increase of the amount of lead sulphate and the increased time;

I Lead sulphate can react with chloride ions when added to the cement concrete material. This reduces the amount of free chloride ions in the concrete, which has a positive effect in the protection of reinforcing steel from corrosion in concrete structures.

I It will produces sulphate damage when lead sulphate is added to the cement concrete material, which have a negative effect on the transport of chloride ions in cementitious materials. The vary negative effect increases with the increase of lead sulfate content and natural infiltration time. Before a 90 days natural infiltration, the negative effect is less than the positive effect. The protection of steel is useful from the transport point of view. When the lead sulfate content is $6 \%$ and the permeation time is 140 days, the negative effect becomes dominant.

\section{Acknowledgements}

The authors gratefully acknowledge the financial support provided by the General Program of the National Natural Science Foundation of China (No.51478272), the joint funds of the National Natural Science Foundation and Guangdong Province of China (U1301241), the International Cooperation and Exchange of the National Natural Science Foundation of China (51520105012), the Science and Technology Foundation for the Basic Research Plan of Shenzhen City (JCYJ20160422095146121), and the Collaborative Innovation Research Centre for Environment-Friendly Materials and Structures in Civil Engineering, Southeast University.

\section{References}

[1] P.S. Mangat, K. Gurusamy: Cem. Concr. Res. 17(3) (1987)385-396.

[2] L.Y. Li, E. Dave, J. Xia, W.L. Jin: Cem. Concr. Compos. 63(2015)113-121.

[3] C. Xie, H.D. Yan: Mater. Rev. 28(7) (2014)101-106.

[4] X.F. Wang, F. Xing, M. Zhang, N.X. Han, Z.W. Qian: Mater. 6(9) (2013)4064-4081.

[5] X.F. Wang, P.P. Sun, N.X. Han, F. Xing: Mater. 10(1) (2017) 1-18.

[6] X.F. Wang, F. Xing, Q. Xie, N.X. Han, T. Kishi, T.H, Ahn: J. Ceram. Process. Res. 16(1) (2015)74-82.

[7] W. Xiong, J.N. Tang, G.M. Zhu, N.X. Han, E. Schlangen, B.Q. Dong, X.W. Wang, F. Xing: Sci. Rep. 5(1) (2015)10866.

[8] A.E. Idiart: Coupled analysis of degradation processes in concrete specimens at the meso-level, Universitat politecnica De catalunya, 2009.

[9] Y.H. He, G.M. Zhu, Z.P. Wu, Y.M. Zhou: J. Funct. Mater. 46(2) (2015)2144-2147+2152. 
[10] Nord-test Method, Concrete, hardened: accelerated chloride penetration, NT Build 443, Helsinfors, 1995.

[11] AASHTO, Standard method of test for Sampling and Testing for Chloride Ion in Concrete and Concrete Raw Materials, AASHTO T 260-97, Washington, 2009.

[12] P.K. Mehta: Cem. Concr. Res. (13) (1983) 401-406. 